\title{
Vulnerability of a Top Marine Predator in One of the World's Most Impacted Marine Environments (Arabian Gulf)
}

\author{
Bruno Diaz Lopez ( $\nabla$ bruno@thebdri.com ) \\ Bottlenose Dolphin Research Institute BDRI https://orcid.org/0000-0002-0388-3289 \\ Séverine Methion \\ Bottlenose Dolphin Research Institute BDRI \\ Himansu Das \\ EAD: Environment Agency Abu Dhabi \\ Ibrahim Bugla \\ EAD: Environment Agency Abu Dhabi \\ Maitha Al Hameli \\ EAD: Environment Agency Abu Dhabi \\ Hind Al Ameri \\ EAD: Environment Agency Abu Dhabi \\ Ahmed Al Hashmi \\ EAD: Environment Agency Abu Dhabi \\ Edwin Grandcourt \\ EAD: Environment Agency Abu Dhabi
}

\section{Research Article}

Keywords: Habitat use, conservation, Bottlenose dolphin, Arabian Gulf, Trans-frontier conservation areas

Posted Date: March 3rd, 2021

DOl: https://doi.org/10.21203/rs.3.rs-261833/v1

License: (1) (1) This work is licensed under a Creative Commons Attribution 4.0 International License. Read Full License 


\section{Abstract}

Knowledge of the habitat use of wildlife in highly impacted areas is essential to identify areas of biological importance and to implement appropriate conservation measures. The Arabian Gulf represents one of the most extreme marine environments and is considered one of the regions in the world with the greatest anthropogenic impact. Information on the habitat use and abundance of marine top predator species is however lacking, despite being a prerequisite for effective planning of conservation measures. Here, we provide novel information for the Indo-Pacific bottlenose dolphin (Tursiops aduncus) in the Arabian Gulf (Abu Dhabi, United Arab Emirates). Data from 80 daily surveys conducted between June 2014 and November 2019 were used both to assess correlates of bottlenose dolphin habitat use and relative density and to calculate mark-recapture abundance estimates. This study confirms the strong adaptability and tolerance of this top marine predator to extreme environmental conditions within a highly heterogeneous and impacted marine habitat. The observed preferences for areas with less human pressure were likely a result of the interactions of environmental factors with prey availability and human disturbance. This study also provides the first abundance estimates for a bottlenose dolphin population in the Arabian Gulf. Our findings support the call for increased marine protected areas and the creation of transboundary conservation areas in the region. Regional connectivity should be of value to marine predators whose wide distribution and vulnerability to human activities means that alteration of their habitats can result in population declines and eventual local or regional extinctions.

\section{Introduction}

As relatively large top predators, dolphins are key component of marine ecosystems. These small cetaceans fulfil "umbrella" and "flagship" criterion and are of high ecological value (Connor et al. 2000). Bottlenose dolphins (Tursiops spp.), despite being widely considered some of the most adaptable of the world's cetaceans, are highly susceptible to environmental changes (Bejder et al. 2006; Sprogis et al. 2018; Díaz López 2019; Methion and Díaz López 2019). Due to their inshore distribution and life history characteristics (i.e., relatively large size, slow growth, late maturation, long gestation period, single births at a time, and long calving interval), bottlenose dolphins are vulnerable to a range of anthropogenic impacts such as habitat modification, overfishing, noise and chemical pollution, bycatch, and boat strikes (Díaz López 2006; Wang and Yang 2009).

The International Union for the Conservation of Nature (IUCN) has recently assigned the Indo-Pacific bottlenose dolphin (Tursiops aduncus, hereafter bottlenose dolphin) the category of "Near Threatened" in light of its nearshore distribution, local declines, and of the increasing intensity of threats to the species (Braulik et al. 2019). There is however a lack of information on habitat use and population abundance throughout much of the species' range, and it is likely that some bottlenose dolphin populations could be classified as "Threatened", particularly in habitats where rapid recent economic, social, and industrial development has not been adequately compensated by conservation measures (Braulik et al. 2019).

The Arabian Gulf (also known as the Persian Gulf and referred to hereafter as the Gulf) represents one of the most extreme and anthropogenically impacted marine environments (Halpern et al. 2008). The Gulf supports a wide variety of marine ecosystems (including seagrass beds, mangroves, coral reefs, and marshes) that are uniquely adapted to extremes of sea surface salinity and temperature and low levels of primary production (Sheppard et al. 2019). Coastal environments in the Gulf are affected by intensive dredging and reclamation activities and various sources of noise and chemical pollution (e.g. seismic surveys for oil and gas, marine traffic, industrial waste, brackish wastewater, ports and refineries, oil spills and domestic wastewater) (Sheppard et al. 2010; Vaughan et al. 2019). Although it is well known that the extreme environmental conditions and anthropogenic activities affect the diversity, abundance, and distribution of many marine species in this region (Sheppard et al. 2010), there is a lack of information on top marine predators' ecology. In particular, there is a paucity of data on bottlenose dolphin ecology, a species regularly present in the Gulf, which prevents a comprehensive assessment of its conservation status (Baldwin et al. 1999; Preen 2004; Díaz López et al. 2018). Obtaining further information on bottlenose dolphin ecology such as on habitat use, site fidelity, abundance estimation, and potential overlapping with human activities would therefore be essential to ensure the persistence of this species in these waters.

With little information available on the distribution and abundance of cetaceans in the Gulf, a collaborative project between the Environment Agency - Abu Dhabi (EAD) and the Bottlenose Dolphin Research Institute (BDRI) was initiated in 2014 to study cetacean ecology in the Southern Arabian Gulf (Abu Dhabi Emirate, United Arab Emirates UAE). In this study, the objective was to provide novel information on bottlenose dolphin ecology and vulnerability to human activities in Abu Dhabi waters. In particular, we identified important habitats for bottlenose dolphins and the environmental factors that affect their presence and abundance in the area. This 
was achieved by examining the relationships between environmental variables and bottlenose dolphin presence and relative abundance. Further, we assessed for the first time the abundance of this species in the region and we identified individual patterns of movement and site fidelity through the use of mark-recapture methods. Based on the findings, we made recommendations to support bottlenose dolphins' conservation in the Southern Arabian Gulf.

\section{Methods}

\subsection{Study area}

This study was conducted along Abu Dhabi Emirate's shoreline. This coast represents about 76 percent of the UAE's Arabian Gulf coast (Abdessalaam 2007). The study area, located between $24.808^{\circ} \mathrm{N} 51.840^{\circ} \mathrm{E}$ and $24.857^{\circ} \mathrm{N} 54.858^{\circ} \mathrm{E}$, comprises approximately $25,000 \mathrm{~km}^{2}$ (Fig. 1). Due to the high geographical latitude, relatively shallow depth and high evaporation rates, the study area is characterized by extreme environmental conditions. This area is influenced by atmospheric processes associated with the winds known as Shamal (i.e. strong, dry and cold northwesterly winds). Shamal winds are stronger during the winter months than during the summer months, being responsible for a drastic reduction in sea surface temperature (oscillating from $15^{\circ} \mathrm{C}$ in winter to $36^{\circ} \mathrm{C}$ in summer) (John et al. 1990). These coastal waters are also characterized by extreme salinity values that can exceed 48 psu (Vaughan et al. 2019). This area has a slightly sloping shelf and comprises different habitats: an extensive coastal sabkha (supra-tidal saline zone, Evans et al. 1969), marshes, mangroves, seagrasses, coral reefs, offshore and coastal islands, the latter forming channel systems. Mangroves, algae and seagrasses cover extensive areas that provide shelter and forage for a multitude of marine species (Abdessalaam 2007). Three cetacean species are present throughout the year: bottlenose dolphins, Indian Ocean humpback dolphins (Sousa plumbea) and finless porpoises (Neophocaena phocaenoides) (Díaz López et al. 2018). While 13.45\% of Abu Dhabi's marine area is currently protected, these coastal waters are experiencing high anthropogenic impact, mainly in the form of the oil and energy industry, and the expansion of the human population leading to land reclamation, port construction, and increased boat traffic and fishing effort (Sheppard et al. 2010; Al Dhaheri et al. 2017).

\subsection{Data collection}

The study area was divided into three different sub-sections based on ecological characteristics and according to logistical constraints (e.g. accessibility, ship launching facilities) (following Díaz López et al. 2018):

1. Eastern Region (between 24808 'N $54800^{\prime} E$ and $24857^{\prime} \mathrm{N} 54858$ 'E, about $4000 \mathrm{~km}^{2}$ ). This region faces the greatest anthropogenic pressure and includes the city of Abu Dhabi (about 1.4 million inhabitants) and inshore islands that delimit a series of natural and man-made channels, seagrass beds, mangrove areas and, in the open coastal waters, coral reefs. This region includes three small Marine Protected Areas: Al Saadiyat $\left(59 \mathrm{~km}^{2}\right)$, Bul Syayeef $\left(145 \mathrm{~km}^{2}\right)$, and Ras Ghanada (54 km²).

2. Central Region (between $24,808^{\circ} \mathrm{N} 53,800^{\circ} \mathrm{E}$ and $24,857^{\circ} \mathrm{N} 54,800^{\circ} \mathrm{E}, 10000 \mathrm{~km}^{2}$ ). This region includes the Marawah Marine Biosphere Reserve (MMBR) (4 $259 \mathrm{~km}^{2}$ ) and surrounding islands, with shallow coastal waters that support habitats with seagrass beds, mangroves, coral reefs, tidal flats, and sabkha.

3. Western region (between $24,808^{\circ} \mathrm{N} 51,840^{\circ} \mathrm{E}$ and $24,857^{\circ} \mathrm{N} 53,800^{\circ} \mathrm{E}, 11000 \mathrm{~km}^{2}$ ). This region is the one with the lowest human population density and the highest diversity of habitats (including extensive seagrass beds, coastal and offshore islands, and coral reefs). It includes the Al Yasat marine protected area $\left(2083 \mathrm{~km}^{2}\right)$,

The surveys were conducted using a 45 -foot custom research vessel powered by two 300-hp outboard engines. We established a systematic daily survey route with transects adapted to the specific conditions of each region, taking into consideration that the vessel was departing from a different harbour within each region. It was not possible to follow a zigzag pattern because the channels, islands, and shallow waters conditioned the trajectory of the transect lines. Each region was monitored for a minimum of three daily surveys for each of the six sampling seasons. A sampling season lasted between 15 and 21 days.

The spatial distribution of the effort varied according to weather conditions and time constraints throughout the study period.

To reduce bias in our ability to detect dolphins, surveys were conducted when visibility was not reduced by rain or fog, wind strength was $<3$ on the Beaufort scale, and wave height was $<0.2 \mathrm{~m}$. Surveys were carried out during daylight hours at a constant speed (between 8 and 10 knots). At least three experienced observers, located on an upper observation deck (2.5 meters above sea level), 
were conducting 360 degrees scan in search of dolphins (with the naked eye and/or with $10 \times 40$ binoculars). In order to include seasonality as a factor in the analysis, sampling seasons were conducted in different months of the year.

On each daily boat-based survey, the date, time, GPS position, boat speed, and environmental data were recorded as an instantaneous sample every 20 minute (Díaz López and Methion 2018). The spatial resolution of this 20-minute interval was $3 \mathrm{~nm}$ (given a speed of 8-10 knots) and dolphin detection/no visual detection was recorded instantly for all 20-minute sampling points. When dolphins were sighted, searching effort ceased and the vessel slowly maneuvered toward them to minimize possible disturbance during approach. A group of bottlenose dolphins was defined as one or more individuals observed within a 100-m radius and, if more than one, interacting with each other and performing the same behavioural activity (Methion and Díaz López 2019). At least two observers with digital SLR cameras equipped with telephoto lenses attempted to photograph both sides of the dorsal fin of each dolphin of the group. Group size and composition were estimated based on the total count of individuals observed at a given time in the area, and the data were later verified during the analysis of the photographs (Methion and Díaz López 2018). The age of the individuals was determined as dependent calves or adults, based on behavioural cues and visual size assessment (Díaz López and Methion 2017). At the end of an encounter, the searching effort continued along the previously planned route.

\subsection{Environmental predictors}

Twelve environmental predictors were considered for each 20-minute sample: date (year and month), time (UTC in hours), latitude and longitude coordinates, depth $(\mathrm{m})$, distance to coast $(\mathrm{m})$, sea surface temperature (SST in ${ }^{\circ}$ Celsius), sea surface salinity (SST in psu), chlorophyll-a concentration (in $\mathrm{mg} \times \mathrm{m}^{-3}$ ) during the day of sampling, chlorophyll-a concentration one month before the day of sampling, and marine benthic habitat type. The depth was extracted from a 30 arc second bathymetric map of the General Bathymetric Chart of the Oceans (GEBCO Compilation Group 2020). The minimum distance of each 20-minute sample from the coast was calculated with the NNJoin plug-in in QGIS 2.18. SST and chlorophyll-a data were obtained as 8-day rasters, with a spatial resolution of $4 \mathrm{~km} \times 4 \mathrm{~km}$ from the Giovanni online data system (Acker and Leptoukh 2007). The SSS was obtained as monthly rasters, with a spatial resolution of 0.5 degrees, from the COPERNICUS Marine Environment Monitoring Service website (http://marine.copernicus.eu). The marine habitat type was obtained from a 5-m resolution Quick Eye Image created by the Environment Agency - Abu Dhabi (EAD), including six different types: coral reef, deep subtidal sea floor, dredged areas, hard bottom, seagrass bed, and unconsolidated bottom. The "point sampling" tool in QGIS 2.18 was then used to extract raster values from multiple layers in each 20-minute sample in order to link bottlenose dolphin relative presence or abundance to environmental predictors.

\subsection{Data analysis and modelling framework}

For the spatial analysis of the observation effort, the study area was divided into $3 \mathrm{~nm}$ hexagonal cells creating a polygon grid using the QGIS software. The size and shape of the cells were designed to fit both the visual area of the research vessel and the distance covered between each 20-min sample (Giralt Paradell et al. 2019). The number of 20-min samples collected within a cell was considered a fair representation of the survey effort.

A generalized additive modelling (GAM) framework was used to explore the predictors that could have affected the two response variables selected in this study: the presence (habitat use) and number of bottlenose dolphins (relative abundance). GAMs are widely used to interpret ecological interactions and are particularly suited to the type of non-linear responses expected in speciesenvironment relationships (Hastie and Tibshirani 1990). The data exploration protocols described by Zuur et al. (2010) were used to identify outliers, data variability, and relationships between predictors and the response variable. Modelling was initiated using a General Linear Model (GLM), which included 12 covariates (latitude and longitude, year, month, observation effort, depth, distance from shore, SST, SST, chlorophyll-a concentrations during the day of sampling and one month prior to sampling, and marine benthic habitat type) that could potentially drive the response variable. Before fitting the model, possible co-linearity between the predictors was investigated by calculating the Spearman correlation coefficients in pairs ( $r$ ) and the variance inflation factors (VIF). When the variables showed a high correlation (above $r=0.7$ and VIF $>3$ ) they were not used together in the same model (Dormann et al. 2013). To find a set of explanatory variables that do not contain collinearity, the variables were eliminated one by one and the VIF values were then recalculated. Following this procedure, the month of the year was excluded before starting the model fit as it was related to other variables which were instead included due to their biological interpretability (SST and SSS, Kruskall-Wallis test, $\mathrm{P}<0.01$ ).

The use of two types of GAMs in this study, with presence-absence data and relative abundance data, allowed an accurate prediction of the response variables (Howard et al. 2014). To choose the most appropriate presence-absence model to address an apparently 
zero-inflated dataset, three different models such as GAMs with logistic link function, Tweedie or Negative Binomial distributions were compared using the Akaike Information Criterion (AIC) (Díaz López et al. 2019). The number of bottlenose dolphins was modelled using a GAM with a negative binomial distribution and logarithmic link function. The smooth functions were constructed as cubic splines and their optimal shape were estimated by minimising the general cross validation (GCV) criterion. The optimal model was selected using a combination of backward and forward model selection procedures based on the corrected Akaike Information Criteria (AICc). Model assumptions were checked by visual inspection of the residuals and regression fits were examined using plots of residuals against fitted values. The final model was the model with the lowest AICc given that effects of all explanatory variables retained in the model were statistically significant and there were no clear patterns in the residuals (Hastie and Tibshirani 1990). The GAMs results and diagnostic information about the fitting procedure were implemented from the mgcv (Wood, 2006) and MASS (Venables and Ripley 2002) packages in v. 1.8.1. of the statistics and graphics tool R (R Development Core Team, 2011). The DurbinWatson test (from the R package "Imtest", Zeileis and Hothorn 2002) and auto-correlation functions (ACF) were used to check for serial correlation, both in the raw data and in the residuals from the models. Partial predictions with $95 \%$ confidence intervals were plotted for each covariate included within the final model. The data are presented as means \pm standard error (SE). To determine the areas of highest predicted probability for the presence of bottlenose dolphins, partial predictions in $\mathrm{R}$ were calculated using the final model. For variables that vary over time (e.g. SST, SSS), mean values were calculated. Predicted values were made on the response scale (between 0 and 1) and displayed on a map using the centroids of $3 \mathrm{~nm} \times 3 \mathrm{~nm}$ hexagonal cells.

\subsection{Analysis of photographs and mark-recapture abundance models}

Bottlenose dolphins were identified based on the natural markings present on their dorsal fins following the methods of selection and photo-identification analysis described in Methion and Díaz López (2018). Only photographs with good and excellent quality conditions were used. Likewise, only distinctly marked adult bottlenose dolphins were included in the photo-identification analysis. Photographs containing calves (immature and newborn dolphins) and unmarked individuals were excluded. Using POPAN in SOCPROG 2.8, abundance estimates were calculated and fitted to four open population mark-recapture models described in Whitehead (2009): 'mortality', 'mortality + trend', 'reimmigration', and 'reimmigration + mortality'. These models require five assumptions to be met: 1) All adult bottlenose dolphins have the same survival probability. 2) All adult bottlenose dolphins have the same capture probability. 3) Marks are not lost or overlooked. 4) Photo-identified bottlenose dolphins are representative of the population being estimated. 5) The duration of each capture occasion is instantaneous in relation to the intervals between sessions. The selection of the most appropriate model was based on the lowest AIC.

Total abundance was calculated using estimates generated from the most appropriate model and corrected for the proportion of distinctly marked individuals in the population. To calculate the proportion of distinctly marked individuals in the population, the number of distinctly marked adult individuals was divided by the total number of individuals observed in each group, averaged across all encounters (Methion and Díaz López 2018). The 95\% confidence intervals were calculated using the "delta method" (Seber 1982).

\section{Results}

\subsection{Survey effort and presence of bottlenose dolphins}

Between June 2014 and November 2019, 80 daily surveys were conducted covering 9933 km (Table 1). In total, 527 hours were spent in satisfactory conditions and 1547 samples were collected. Overall, 89 groups of bottlenose dolphins were encountered (Fig. 1). A total of 757 bottlenose dolphins were sighted on 34 different days (42.5\% of the total number of daily surveys) during seven different months. Bottlenose dolphins were found in all three monitored regions throughout the study area and during both the warm (AprilSeptember) and cold (October-March) seasons. Groups of bottlenose dolphins were observed in seagrass and deep-subtidal seabed, dredged areas, and both hard and unconsolidated sea bottoms. Group size ranged from 1 to 45 (mean $=8.51 \pm$ SE 0.90$)$ and most groups (88.9\%) had 20 or fewer individuals. There was no evidence of a difference in group size between the monitored areas (Kruskal-Wallis test, $\mathrm{P}>0.05$ ) (Table 2). Regarding group composition, $76.1 \%$ of the observed dolphins were considered adults, $20.9 \%$ immature dolphins, and $3 \%$ newborn dolphins. Dependent calves were present in $86.1 \%$ of the observed groups. Group size was significantly related to the number of dependent calves in the group (Spearman rho $=0.69, P<0.001)$. Likewise, group size was significantly larger in the presence of dependent calves (mean with calves $=10.7 \pm S E 1.2$ vs. mean without calves $=3.8 \pm S E 0.5$; Mann-Whitney, $\mathrm{P}<0.001)$. In two encounters throughout the study, bottlenose dolphins were observed in mixed feeding aggregations with Indian Ocean humpback dolphins.

Page 5/16 
Table 1

Distribution of the observation effort, the number of bottlenose dolphin encounters (S), and number of individuals photo-identified across the three monitored regions.

\begin{tabular}{|c|c|c|c|c|c|}
\hline \multirow[t]{2}{*}{ Region } & \multicolumn{3}{|c|}{ Observation effort } & \multirow[t]{2}{*}{ Bottlenose dolphin encounters } & \multirow[t]{2}{*}{ Bottlenose dolphins identified } \\
\hline & Days & Hours & 20-min samples & & \\
\hline Eastern & 27 & 188 & 565 & 9 & 41 \\
\hline Central & 31 & 191 & 561 & 23 & 130 \\
\hline Western & 22 & 148 & 421 & 57 & 286 \\
\hline Total & 80 & 527 & 1547 & 89 & $457 *$ \\
\hline
\end{tabular}

* This value is higher than the total number of bottlenose dolphins identified (379 individuals) because some individuals were identified in more than one region.

Table 2

Bottlenose dolphin group sizes (mean \pm SE) observed during the study

$(\mathrm{G})$, including all age-classes $(\mathrm{A}=$ Adults, $\mathrm{Im}=\mathrm{Immatures}, \mathrm{Nb}=\mathrm{New}-$

borns).

\begin{tabular}{|lllll|}
\hline Region & G & A & Im & Nb \\
\hline Eastern & $10.22 \pm 2.75$ & $6.89 \pm 1.79$ & $2.78 \pm 0.78$ & $0.56 \pm 0.34$ \\
\hline Central & $7.52 \pm 1.44$ & $5.52 \pm 0.97$ & $1.70 \pm 0.42$ & $0.30 \pm 0.18$ \\
Western & $8.63 \pm 1.22$ & $6.86 \pm 0.99$ & $1.54 \pm 0.25$ & $0.19 \pm 0.08$ \\
\hline Total & $8.51 \pm 0.90$ & $6.52 \pm 0.70$ & $1.71 \pm 0.21$ & $0.26 \pm 0.08$ \\
\hline
\end{tabular}

\subsection{Environmental drivers of bottlenose dolphin presence}

The most parsimonious model to fit the data was a GAM with a logistic link function with eight variables (Table 3). The GAM explained $22.6 \%$ of the variation in bottlenose dolphin presence (AICc 31.1 units lower than the initial model). Bottlenose dolphin presence was predicted to be significantly influenced by location (latitude, longitude, and distance from shore), SST, and chlorophyll-a concentration one month prior to the sampling date (Supplementary Information S1). It was predicted that bottlenose dolphin occurrence was more likely in the central and western regions of Abu Dhabi (Fig. 2). Observation effort, SSS, and chlorophyll-a concentration during the sampling date did not significantly contribute to the observed variation in bottlenose dolphin occurrence $(P>$ 0.05). 
Table 3

Summary of the final GAM on the presence of bottlenose dolphins selected by a backward-forward stepwise procedure. edf $=$ effective degrees of freedom for the spline smoother. $\mathrm{Chi}$ sq $=$ Chi square test value. $\mathrm{CHL}-\mathrm{a}(-30 \mathrm{~d})=$ concentration of chlorophyll-a one month before the sampling date. R-Sq (adj) = adjusted rsquared for the model. UBRE = unbiased risk estimator.

\begin{tabular}{|llll|}
\hline Selected variable & edf & Chi sq & P-value \\
\hline Latitude & 1.2 & 13.0 & $<0.0001$ \\
\hline Longitude & 2.4 & 23.3 & $<0.0001$ \\
\hline Effort & 4.0 & 8.2 & 0.08 \\
\hline Distance of the coast & 2.2 & 8.4 & 0.01 \\
\hline SST & 2.1 & 6.0 & 0.04 \\
\hline SSS & 7.8 & 9.8 & 0.20 \\
\hline CHL-a & 2.5 & 5.4 & 0.09 \\
\hline CHL-a (-30d) & 1.0 & 4.8 & 0.01 \\
\hline R-Sq(adj) & 0.126 & & \\
\hline Deviance explained & $22.9 \%$ & & \\
\hline UBRE & -0.62 & & \\
\hline AICc & 523.4 & & \\
\hline$n$ & 1367 & \\
\hline
\end{tabular}

\subsection{Environmental drivers of bottlenose dolphin relative abundance}

Based on AICc scores, the most parsimonious model to fit the data was a GAM with a negative binomial distribution with five variables (Table 4). The GAM explained $47 \%$ of the variation in bottlenose dolphin relative abundance (AICc 161 units lower than the initial model). Bottlenose dolphin relative abundance was predicted to be significantly influenced by the location (latitude, longitude, and type of marine benthic habitat), SSS, and chlorophyll-a concentration one month prior to the sampling date (Supplementary Information S2). Bottlenose dolphin relative abundance was predicted to be higher in the western and central regions of Abu Dhabi. The observed aggregations of bottlenose dolphins were smaller in locations with seagrass bed and hard bottom than those aggregations observed in other types of marine benthic habitat (Fig. 3). 
Table 4

Summary of the final GAM on the number of bottlenose dolphins selected by a backward-forward stepwise procedure. edf $=$ effective degrees of freedom for the spline smoother. Chi $\mathrm{sq}=$ Chi square test value. $\mathrm{CHL}-\mathrm{a}(-30 \mathrm{~d})=$ concentration of chlorophyll-a one month before the sampling date. $\mathrm{R}-\mathrm{Sq}(\mathrm{adj})=$ adjusted r-squared for the model. REML = random effect model for longitudinal data.

\begin{tabular}{|llll|}
\hline Selected variable & edf & Chi sq & P-value \\
\hline Latitude & 1.0 & 9.35 & 0.002 \\
\hline Longitude & 2.9 & 12.4 & 0.007 \\
\hline SSS & 3.3 & 10.0 & 0.02 \\
\hline CHL-a (-30d) & 2.1 & 8.7 & 0.02 \\
\hline Deep-subtidal seabed & & -0.4 (z value) & 0.69 \\
\hline Hard bottom & & -2.0 (z value) & 0.04 \\
\hline Seagrass bed & & -2.5 (z value) & 0.01 \\
\hline Unconsolidated bottom & & -0.6 (z value) & 0.55 \\
\hline R-Sq (adj) & 0.169 & & \\
\hline Deviance explained & $47 \%$ & & \\
\hline REML & 242.5 & & \\
\hline AICc & 508.8 & & \\
\hline $\mathrm{n}$ & 81 & & \\
\hline
\end{tabular}

\subsection{Photographic identification data, mark-recapture model selection, and abundance estimation}

A total of 379 distinctly marked adult bottlenose dolphins were selected for the study. The mean proportion of distinctly marked adult bottlenose dolphins within each group was $0.72 \pm$ SE 0.03 (range $0-1)$. In total, 63 bottlenose dolphins ( $16.6 \%$ of the total number) were identified on more than one day. Most of the bottlenose dolphins $(83.4 \%, n=316)$ were identified during only one of the research years. In contrast, 49 individuals (12.9\%) were sighted during two different years, 13 individuals $(3.4 \%)$ were sighted during three different years, and one individual $(0.3 \%)$ was sighted all four years of research.

During the study, 286 individuals were seen in the western region, 130 individuals in the central region, and 41 individuals in the eastern region. Of the 63 individuals sighted two or more times, 30 individuals were found in a single region (28 in the western region and two in the eastern region), 30 individuals in two regions (17 in the western and eastern region, seven in the western and central region, and six in the central and eastern region), and three individuals in all three regions.

The most appropriate open model showed a population that was declining at a constant rate (Table 5). Population size, mortality rate, and population decline per sampling period were estimated using maximum likelihood. Abundance estimates suggested a population size of $563 \pm 117$ (95\% Cl = 358-932) distinctly marked adult individuals. Based on the proportion of distinctly marked adult bottlenose dolphins $(72 \%), 782(95 \% \mathrm{Cl}=497-1294)$ bottlenose dolphins were estimated to inhabit Abu Dhabi waters. 
Table 5

Open models fitted to the capture histories of bottlenose dolphins to estimate population abundance in Abu Dhabi waters between 2014 and 2018

\begin{tabular}{|c|c|c|c|c|c|c|c|c|c|c|c|c|c|}
\hline \multirow[b]{2}{*}{ Model } & \multirow[b]{2}{*}{$\mathrm{n}$} & \multirow[b]{2}{*}{$\begin{array}{l}95 \% \mathrm{Cl} \\
\star\end{array}$} & \multicolumn{5}{|c|}{ Marked bottlenose dolphins } & \multicolumn{3}{|c|}{ Model Selection } & \multicolumn{3}{|c|}{ Total population } \\
\hline & & & $\begin{array}{l}\mathrm{m} \pm \\
\mathrm{s} . \mathrm{e}\end{array}$ & $\begin{array}{l}\mathrm{T} \pm \\
\text { s.e }\end{array}$ & $\mathrm{e}$ & $r$ & $\mathrm{Nc}$ & $\mathrm{sp}$ & $\begin{array}{l}\text { Log } \\
\text { Likehood }\end{array}$ & AIC & $\varnothing$ & $\mathrm{Nt}$ & $95 \% \mathrm{Cl}$ \\
\hline Mortality & 585.1 & $\begin{array}{l}374.2- \\
960.5\end{array}$ & $\begin{array}{l}0.40 \\
\pm \\
0.12\end{array}$ & n.a & n.a & n.a & 379 & 6 & -203.9 & 411.9 & 0.72 & 812.7 & $\begin{array}{l}519- \\
1334\end{array}$ \\
\hline $\begin{array}{l}\text { Mortality + } \\
\text { Trend }\end{array}$ & 563.3 & $\begin{array}{l}357.5- \\
931.5\end{array}$ & $\begin{array}{l}0.53 \\
\pm \\
0.13\end{array}$ & $\begin{array}{l}-0.34 \\
\pm \\
0.11\end{array}$ & n.a & n.a & 379 & 6 & -200.4 & 406.9 & 0.72 & 782.3 & $\begin{array}{l}497- \\
1294\end{array}$ \\
\hline Reimmigration & 585.3 & $\begin{array}{l}392.5- \\
1022\end{array}$ & n.a & n.a & $\begin{array}{l}0.33 \\
\pm \\
0.08\end{array}$ & $\begin{array}{l}0.00 \\
\pm \\
0.00\end{array}$ & 379 & 6 & -204 & 413.9 & 0.72 & 812.5 & $\begin{array}{l}546- \\
1419\end{array}$ \\
\hline $\begin{array}{l}\text { Reimmigration } \\
\text { + Mortality }\end{array}$ & 584 & $\begin{array}{l}375- \\
881\end{array}$ & $\begin{array}{l}0.19 \\
\pm \\
0.09\end{array}$ & n.a & $\begin{array}{l}0.17 \\
\pm \\
0.08\end{array}$ & $\begin{array}{l}0.00 \\
\pm \\
0.02\end{array}$ & 379 & 6 & -204 & 415.9 & 0.72 & 811 & $\begin{array}{l}521- \\
1224\end{array}$ \\
\hline \multicolumn{14}{|c|}{$\begin{array}{l}\text { Notations: } \mathrm{n}=\text { estimated population size; } \mathrm{CI}=\text { confidence interval; * Bootstrapped }(n=500) \text { SOCPROG Model results; } \mathrm{n} . \mathrm{a}=\mathrm{not} \\
\text { available; } \mathrm{m}=\text { estimated mortality rate; } \mathrm{T}=\text { estimated trend; } \mathrm{e}=\text { estimated emigration rate, } \mathrm{r}=\text { estimated reimmigration rate, Nc = } \\
\text { number of animals captured; s.e. = standard error; s.p.= number of sampling periods; } \emptyset=\text { ratio of marked adult bottlenose } \\
\text { dolphins; } \mathrm{Nt}=\text { estimate of total population size after correcting for proportion of identifiable individuals; AIC = Akaike Information } \\
\text { Criterion. }\end{array}$} \\
\hline
\end{tabular}

\section{Discussion}

\subsection{General importance and impact}

Studies that assess marine top predator habitat use and abundance are fundamental in areas such as the Gulf, where many species live near to their tolerances and are highly impacted by human activities (Sheppard et al. 2010). Our study provides novel information about bottlenose dolphin habitat use, movements, and abundance along Abu Dhabi Emirate coastline. The value of this type of study is well-recognised to identify areas of biological importance and to determine the spatio-temporal scale at which human activities may impact on dolphins, therefore facilitating their conservation (Cheney et al. 2014).

On a broader scale, this study confirms the strong adaptability and tolerance of bottlenose dolphins to extreme environmental conditions within a highly heterogeneous and impacted marine habitat. From a regional perspective, we provide the first estimates of factors conditioning habitat use and relative abundance for bottlenose dolphins in the Gulf. From a local point of view, we show a population of $782(95 \% \mathrm{Cl}=496$ - 1294$)$ individuals decreasing at a constant rate in Abu Dhabi waters. This information advances the work done in 2014 - 2016 estimating the abundance of another top marine predator species (Indian Ocean humpback dolphin) in Abu Dhabi waters (Díaz López et al. 2018) and therefore adds to the knowledge about coastal cetaceans in this highly impacted region.

\subsection{Drivers of habitat use and relative abundance}

Ecological drivers influenced bottlenose dolphin habitat use and relative abundance along the Abu Dhabi coastal waters. Using a multi-year data set and GAMs, we identified location, SSS, SST, and chlorophyll-a concentration as important determinants of bottlenose dolphin habitat use and relative abundance. These observations, together with the results of the mark-recapture analysis, indicated that the species showed preferences for the central and western regions of Abu Dhabi. The observed influence of these environmental factors on bottlenose dolphin presence and relative abundance may be related to the interaction of these factors with changes in abundance and availability of dolphins' prey species. Bottlenose dolphins feed on a wide variety of pelagic, demersal and reef fish, as well as cephalopods (Amir et al. 2005) and SST, SST, and zooplankton abundance substantially affect the availability of these species (Houde et al. 1986; Grandcourt et al. 2005). The relationship between a relatively low concentration of chlorophyll-a concentration one month before the day of sampling and bottlenose dolphin presence could be interpreted as a period of phytoplankton decline mediated by zooplankton grazing and, consequently, the increase of zooplanktivorous fish species. Along Abu 
Dhabi coast, pelagic fish species are most abundant between September and May, and fish generally move in an east-west direction during this period (Grandcourt et al. 2005). Reef fish communities also show seasonal fluctuations with an abundance peak when water temperature is colder (Grandcourt et al. 2011; Grandcourt 2012). Likewise, seaweed beds are more abundant and mix with sea grasses between September and May, which provide a vital settlement and breeding ground for various fish species (George and John 1999).

Our study cannot conclusively prove the direct impact of human disturbance on bottlenose dolphins due to the influence of other explanatory factors such as changes in prey availability. The positive relationship between bottlenose dolphin habitat use and relative abundance and distance from the coast (human settlements) could however be related to dolphin avoidance of elevated anthropogenic activities in coastal waters. Likewise, the higher preferences of bottlenose dolphins for the central and western regions are likely due to less human disturbance in these areas compared to the eastern region (less noise pollution; less marine traffic; less habitat degradation). Compared to the western and central regions, the eastern coast of Abu Dhabi has a higher human population density, has experienced a more rapid population increase, and has fewer marine protected areas. In this region, coastal dredging and development for industrial, commercial, and residential use have induced dramatic changes in marine ecosystems which may indirectly decrease the availability of dolphin's prey species (Sheppard et al. 1992, 2010; Al Dhaheri et al. 2017). Other threats such as pollution and noise are also more prevalent in eastern coastal waters, some of which are difficult to quantify alone or in synergy with others (Gordon et al. 2003). This suggests a potentially significant impact of anthropogenic disturbance on bottlenose dolphins.

\subsection{Abundance estimation}

Our study provides the first population size estimates of bottlenose dolphins for a site in the Gulf. The population estimates indicated that about 782 bottlenose dolphins were using the coastal waters of Abu Dhabi between 2014 and 2019. Reliable population estimates of other bottlenose dolphin populations within the Gulf are urgently needed to allow comparisons and to obtain an adequate assessment of the species' conservation status throughout the region. This population size estimate is roughly comparable to the local Indian Ocean humpback dolphin population studied previously in the same study area (Díaz López et al. 2018). Although the abundance estimate showed a negative trend over the study period, with the lowest number of individuals in the last year of research, this trend could have been influenced by natural variability, such as movements in or out of the study site (Cheney et al. 2014), and other factors affecting our photo-identification data rather than a true decrease in population size. Environmental conditions or slight changes in spatial/temporal survey effort may affect the availability of animals for capture, especially if some animals are transient (as evidenced by the high number of animals captured once during sampling seasons). This may affect the overall probability of capture and increase the heterogeneity of individuals. In this population characterized by low site fidelity and wide-ranging patterns, further research is needed on individual movement patterns, which could be addressed through the use of multi-state models (Williams et al. 2002; Nicholson et al. 2012), collecting data simultaneously in all three regions.

\subsection{Implications for conservation}

Given the importance of location and environmental conditions in shaping bottlenose dolphin habitat use and relative abundance, maintaining sufficient habitat to support prey populations should be a priority for bottlenose dolphin conservation in Abu Dhabi's coastal waters. The results of this study suggest that the Marawah Marine Biosphere Reserve and Al Yasat Marine Protected Area in the central and western regions may have been successful in securing bottlenose dolphin prey in those regions, and also have an important role to play in preserving a small portion of current bottlenose dolphin habitat in the future. Within these protected areas, commercial fishing is prohibited, except by artisanal fishermen using traditional gear, and the capture of any dugong, turtle or marine mammal is prohibited (UAE Federal Law No. 23/1999). Dredging, land filling or other development activities on the coast are also restricted. However, the small size of these marine protected areas, taking into account the distribution and observed movements of bottlenose dolphins, is a clear limitation to contribute to the conservation of suitable habitats for the species. The observed movement of several individual bottlenose dolphins between sites separated by $>250 \mathrm{~km}$ of coastline suggests that movements along these distances are not uncommon for this species. In addition, the lack of information on cetacean bycatch in Abu Dhabi waters makes it difficult to assess the magnitude and population-level impact of fisheries in the area. Future research efforts should focus on assessing the effects of artisanal fishing gear, particularly traps and gillnets, on bottlenose dolphin populations.

In addition to preserving and increasing marine protected areas within these waters and conducting future studies on the impact of fisheries on dolphin populations, regional connectivity should be of particular value for bottlenose dolphins and other coastal cetacean species since alteration of their coastal habitats can result in population declines and eventual local or regional extinctions 
(Barlow et al. 2010; Mei et al. 2012). Our results shed light on the importance of transnational research on the distribution of cetaceans in the waters of the Gulf for the establishment of trans-frontier conservation areas (TFCAs). TFCA countries under the umbrella of the Gulf Cooperation Council Biodiversity Committee (GCCBC) should develop and implement regional action and management plans for the conservation of marine mammal species across borders. The oceanography of the Gulf and projections of the future climate of the region are sufficient reasons to believe that coastal cetacean species are seriously threatened by anthropogenic activities. We therefore recommend further research to identify important corridors for cetaceans within the coastal waters of the Gulf and establish collaboration between researchers and different stakeholders to ensure their integration into management plans.

\section{Declarations}

Funding: This research has been funded by the Environment Agency - Abu Dhabi (EAD).

Conflict of interest/Competing interests: The authors declare that they have no known competing financial interests or personal relationships that could have appeared to influence the work reported in this paper.

Availability of data and material: Data will be provided under request.

Code availability: R Script will be provided under request.

Authors' contribution: B.D.L., S.M., H.D, I.B., M.A.H, and E.G collected the data during the study. B.D.L. analysed the data with input from S.M. B.D.L. wrote the manuscript with significant input from S.M., and H.D. B.D.L and S.M. conceived and designed the study. All authors contributed critically to the manuscript.

Ethics approval: Data collection complies with the current laws of Abu Dhabi, the country in which it was performed. The research adheres to the legal requirements of the country in which the work was carried out (Emirate of Abu Dhabi, UAE), and all institutional guidelines.

Consent to participate: All authors gave final approval to participate.

Consent for publication: All authors gave final approval for publication.

\section{Acknowledgments}

Thanks to the volunteers who came along to help with fieldwork. Data collection complies with the current laws of the country in which it was performed, Abu Dhabi (UAE). We dedicate this study to our colleague Edwin Grandcourt who passed away during the period of this research.

\section{References}

Abdessalaam, T.Z. 2007. Marine environment and resources of Abu Dhabi. Environment Agency - Abu Dhabi: Motivate Publishing (UAE). 255 pp.

Acker, J.G. and Leptoukh, G. 2007. Online Analysis Enhances Use of NASA Earth Science Data, Eos, Trans. Am. Geophys. Union. 88(2), $14-17$.

Al Dhaheri, S.S., Al Cibahy, A., Javed, A., Grandcourt, E., Bin Kulaib, R., and Al Mazrouei, S. 2017. Abu Dhabi state of environment report 2017: Biodiversity. Environment Agency - Abu Dhabi. Abu Dhabi, UAE. 48pp.

Amir, O.A., Berggren, P., Ndaro, S.G.M., and Jiddawi, N.S. 2005. Feeding ecology of the Indo-pacific bottlenose dolphin (Tursiops aduncus) incidentally caught in the gillnet fisheries off Zanzibar, Tanzania. Estuar. Coast. Shelf Sci. 63, 429-437.

Baldwin, R.M., Van Waerebeek, K. \& Gallagher, M. (1999). A review of cetaceans from waters off the Arabian Peninsula. In Gallagher, M., Fisher, M., Ghazanfar, S.A. and Spalton, J.A. (eds). pp. 161-189. The natural history of Oman. A Festschrift for Michael Gallagher. Leiden: Backhuys Publishers (Netherlands). 
Barlow, J., Rojas-Bracho, L., Munoz-Pina, C., \& Mesnick, S. (2010). Conservation of the vaquita (Phocoena sinus) in the Northern Gulf of California, Mexico. In R. Q. Grafton, R. Hilborn, D. Squires, M. Tait, M. Williams (eds). pp. 205-214. Marine fisheries conservation and management. Oxford University Press, New York (USA).

Bejder, L., Samuels, A.M.Y., Whitehead, H.A.L., Gales, N., Mann, J., Connor, R., Heithaus, M., Watson-Capps, J., Flaherty, C., \& Krützen, M. (2006). Decline in relative abundance of bottlenose dolphins exposed to long-term disturbance. Conserv. Biol. 20(6), 1791-1798.

Braulik, G., Natoli, A., Kiszka, J., Parra, G., Plon, S., \& Smith, B.D. (2019). Tursiops aduncus. The IUCN Red List of Threatened Species 2019: e.T41714A50381127.

Cheney, B., Corkrey, R., Durban, J.W., Grellier, K., Hammond, P.S., Islas-Villanueva, V., Janik, V.M., Lusseau, S.M., Parsons, K.M., Quick, N.J. \& Wilson, B. (2014). Long-term trends in the use of a protected area by small cetaceans in relation to changes in population status. Glob. Ecol. Conserv. 2, 118-128.

Connor, R. C., Wells, R. S., Mann, J., \& Read, A. J. (2000). In J. Mann, R. Connor, P. L. Tyack, \& H. Whitehead (Eds.), The bottlenose dolphin: Social relationships in a fission-fusion society. Cetacean societies: field studies of dolphins and whales (pp. 91-126). Chicago, IL: University of Chicago Press (USA).

Díaz López, B. (2006). Interactions between Mediterranean bottlenose dolphins (Tursiops truncatus) and gillnets off Sardinia, Italy. ICES J. Mar. Sci. 63, 946-951.

Díaz López, B. (2019). 'Hot deals at sea': Responses of a top predator (bottlenose dolphin, Tursiops truncatus) to human-induced changes in the coastal ecosystem. Behav. Ecol. 30(2), 291-300.

Díaz López, B. \& Methion, S. (2017). The impact of shellfish farming on common bottlenose dolphins' use of habitat. Mar. Biol. 164(4), 83.

Díaz López, B. \& Methion, S. (2018) Does interspecific competition drive patterns of habitat use and relative density in harbour porpoises? Mar. Biol. 165, 92.

Díaz López, B., Grandcourt, E., Methion, S., Das, H., Bugla, I., Al Hameli, M., Al Hameri, H., Abdulla, M., Al Blooshi, A., \& Al Dhaheri, S. (2018). The distribution, abundance and group dynamics of Indian Ocean humpback dolphins (Sousa plumbea) in the Emirate of Abu Dhabi (UAE). J. Mar. Biol. Assoc. U.K. 98(5), 1119-1127.

Díaz López, B., Methion, S., \& Giralt Paradell, O. (2019). Living on the edge: Overlap between a marine predator's habitat use and fisheries in the Northeast Atlantic waters (NW Spain). Prog. Oceanogr. 175, 115 - 223.

Dormann, C.F., Elith, J., Bacher, S., Buchmann, C., Carl, G., Carré, G., Marquéz, J.R.G., Gruber, B., Lafourcade, B., Leitão, P.J., \& Münkemüller, T. (2013). Collinearity: a review of methods to deal with it and a simulation study evaluating their performance. Ecography. 36 (1), 27-46.

Evans, G., Schmidt, V., Bush, P., \& Nelson, H. (1969). Stratigraphy and geologic history of the sabkha, Abu Dhabi, Persian Gulf. Sedimentology. 12, 145-159.

GEBCO Compilation Group (2020) GEBCO 2020 Grid (doi:10.5285/a29c5465-b138-234d-e053-6c86abc040b9)

Giralt Paradell, O., Díaz López, B., \& Methion, S. (2019). Modelling common dolphin (Delphinus delphis) coastal distribution and habitat use: Insights for conservation. Ocean Coast Manag. 179, 104836.

Gordon, J., Gillespie, D., Potter, J., Frantzis, A., Simmonds, M. P., Swift, R., \& Thompson, D. (2003). A review of the effects of seismic surveys on marine mammals. Mar. Technol. Soc. J. 37(4), 16-34.

Grandcourt, E. M. (2012). Reef fish and fisheries in the Gulf. In Coral Reefs of the Gulf, pp. 127-161. Ed. by B. M. Riegl and S. J. Purkis. Springer, Dordrecht, Netherlands. 
Grandcourt, E. M., Al Abdessalaam, T. Z., Francis, F., \& Al Shamsi, A. T. (2005). Preliminary assessment of the biology and fishery for the narrow-barred Spanish mackerel, Scomberomorus commerson (Lacépède, 1800), in the southern Arabian Gulf. Fish. Res. 76(2), 277-290.

Grandcourt, E., Al-Cibahy, A., Al-Harthi, S. S., \& Bugla, I. (2011). The abundance, status and bio-economic production potential of coral reef fisheries resources in Abu Dhabi. Biodiversity management sector. Environment Agency - Abu Dhabi. Abu Dhabi, UAE. 48pp.

George, D. \& John, D. (1999). High sea temperatures along the coast of Abu Dhabi (UAE) Arabian Gulf - their impact upon corals and macroalgae. Reef Encounter 25, 21-23.

Halpern, B. Walbridge, S. Selkoe, K. Kappel, C. Micheli, F. D’Agrosa, C. Bruno, J. Casey, K. Ebert, C. Fox, H. Fujita, R. Heinemann, D. Lenihan, H. Madin, E. Perry, M. Selig, E. Spalding, M. Steneck, R., \& Watson, R. (2008). A global map of human impact on marine ecosystems. Science, 319, 948-952.

Hastie, T.J. \& Tibshirani, R.J. (1990). Generalized additive models. Chapman and Hall, London. 352pp.

Houde, E.D., Almatar, A.H., Leak, J.C., \& Down, C.E. (1986). Ichthyoplankton abundance and diversity in the western Gulf. Kuwait Bull. Mar. Sci. 8, 60 .

Howard, C., Stephens, P.A., Pearce-Higgins, J.W., Gregory, R.D., \& Willis, S.G. (2014). Improving species distribution models: the value of data on abundance. Methods Ecol. Evol. 5 (6), 506-513.

John, V., Coles, S., \& Abozed, A. (1990). Seasonal cycles of temperature, salinity and water masses of the western Arabian Gulf. Oceanol. Acta. 13, 273-281.

Mei, Z., Huang, S. L., Hao, Y., Turvey, S. T., Gong, W., \& Wang, D. (2012). Accelerating population decline of Yangtze finless porpoise (Neophocaena asiaeorientalis asiaeorientalis). Biol. Conserv. 153, 192-200.

Methion, S. \& Díaz López, B. (2018). Abundance and demographic parameters of bottlenose dolphins in a highly affected coastal ecosystem. Mar. Freshw. Res. 69(9), 1355-1364.

Methion, S. \& Díaz López, B. (2019). Natural and anthropogenic drivers of foraging behaviour in bottlenose dolphins: influence of shellfish aquaculture. Aquat Conserv. 29(6), 927-937.

Preen, A. (2004). Distribution, abundance and conservation status of dugongs and dolphins in the southern and western Arabian Gulf. Biol. Conserv. 118, 205-218.

Seber, G. A. F. (1982). The estimation of animal abundance and related parameters. Macmillan Publishing Co., New York, NY. 506pp.

Sheppard, C., Price, A., \& Roberts, C. (1992). Marine ecology of the Arabian region: patterns and processes in extreme tropical environments. Academic Press, London. 359pp.

Sheppard, C. Al-Husiani, M. Al-Jamali, F. Al-Yamani, F. Baldwin, R. Bishop, J. Benzoni, F. Dutrieux, E. Dulvy, N. Durvasula, S. Jones, D. Loughland, R. Medio, D. Nithyanandan, M. Pilling, G. Polikarpov, I. Price, A. Purkis, S. Riegl, B. Saburova, M. Namin, K. Taylor, O. Wilson, S. \& Zainal, K. (2010). The Gulf: A young sea in decline. Mar. Pollut. Bull. 60, 3-38.

Vaughan, G. O., Al-Mansoori, N., \& Burt, J. A. (2019). The Arabian Gulf. In: C. Sheppard (ed), World seas: An environmental evaluation, Volume II: the Indian Ocean to the Pacific (pp. 1-23). Academic Press (USA).

Venables, W.N. \& Ripley, B.D. (2002). Modern Applied Statistics with R. Fourth edition. Springer, New York (USA). 495pp.

Wang, J.Y. \& Yang, S. C. (2009). Indo-Pacific bottlenose dolphin: Tursiops aduncus. In: In: W. F. Perrin, B. Wursig and J. G. M. Thewissen (eds), Encyclopedia of marine mammals (pp. 602-608). Academic Press.

Whitehead, H. (2009). SOCPROG programs: analysing animal social structures. Behav. Ecol. Sociobiol. 63(5), 765-778.

Wood, S.N. (2006). Generalized Additive Models, An Introduction with R. CRC Press, Taylor \& Francis Group, Florida (USA). 392pp.

Page $13 / 16$ 
Zuur, A.F., leno, E.N., \& Elphick, C.S. (2010). A protocol for data exploration to avoid common statistical problems. Methods Ecol. Evol. $1(1), 3-14$.

Figures

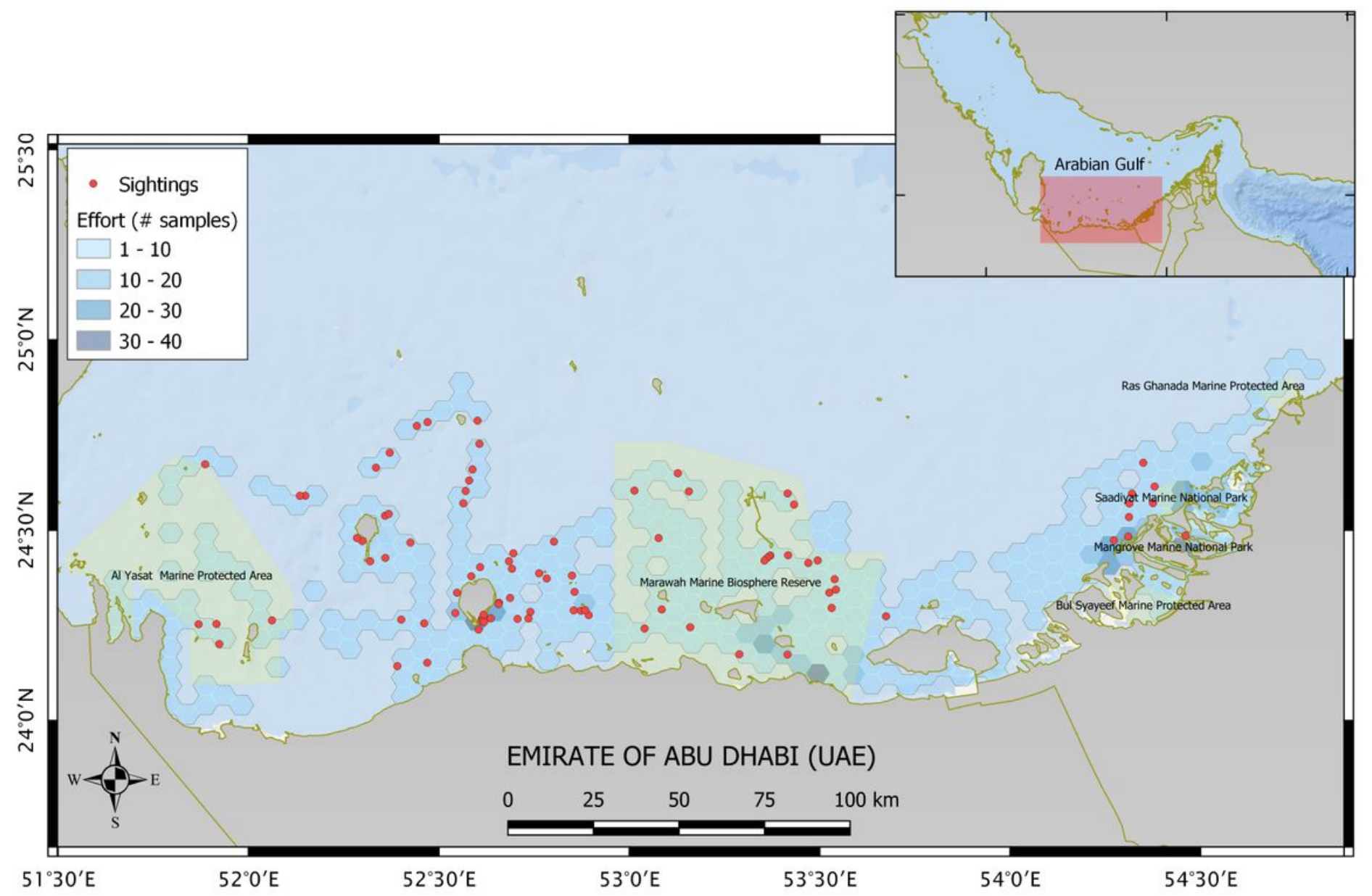

\section{Figure 1}

Map of the study area surveyed along the coastline of the Emirate of Abu Dhabi (UAE), showing the sightings of bottlenose dolphins and the MPAs. The grid corresponds to the distribution of the survey effort in each $3 \mathrm{~nm}$ cell (number of samples collected instantaneously every $20 \mathrm{~min}$ ). Note: The designations employed and the presentation of the material on this map do not imply the expression of any opinion whatsoever on the part of Research Square concerning the legal status of any country, territory, city or area or of its authorities, or concerning the delimitation of its frontiers or boundaries. This map has been provided by the authors. 


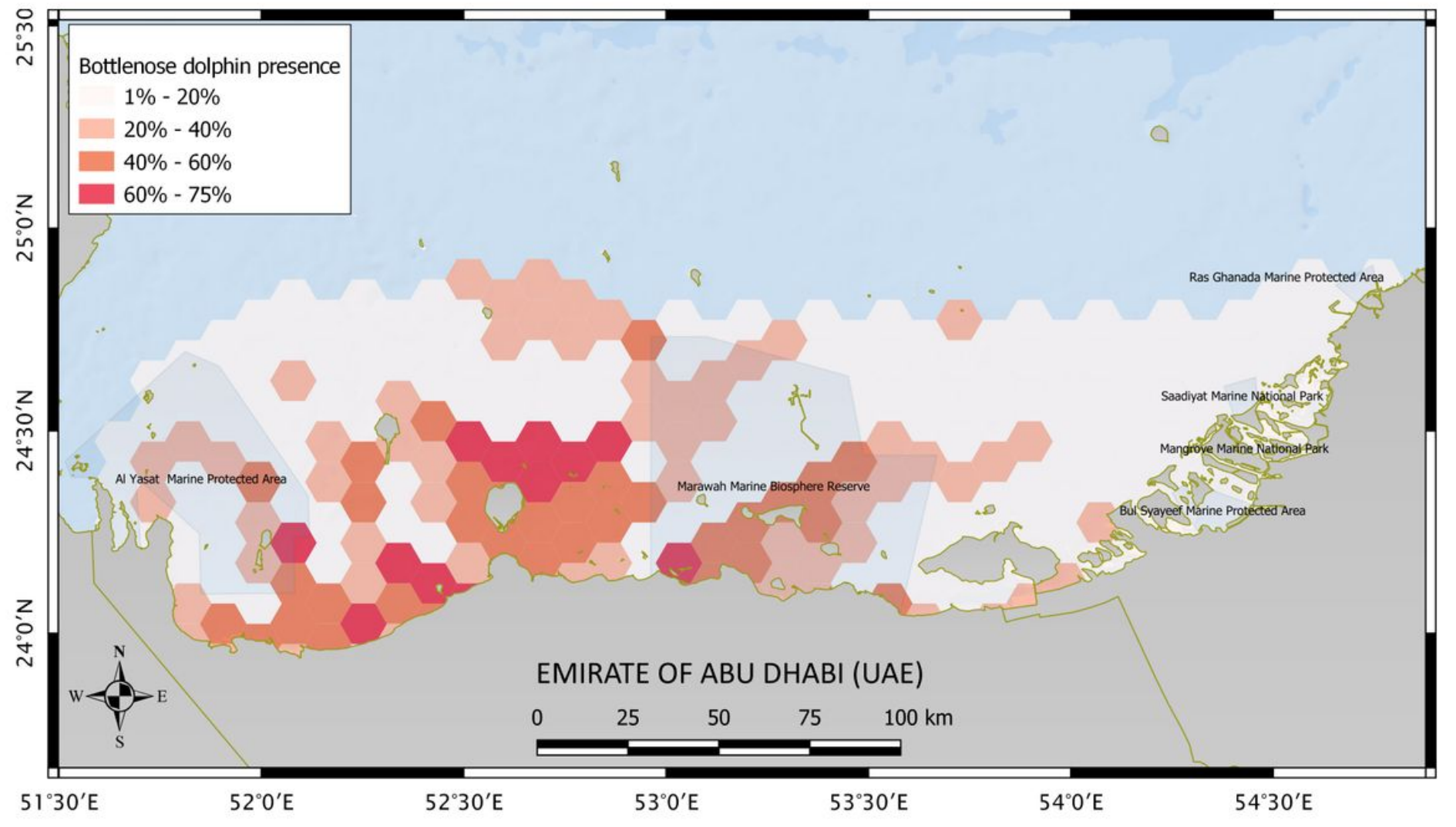

Figure 2

Areas of higher predicted probability of encountering bottlenose dolphins. The predicted values were made on the response scale (probability in \%) in each $3 \mathrm{~nm} \times 3 \mathrm{~nm}$ hexagonal cell. Datum = WGS84. Note: The designations employed and the presentation of the material on this map do not imply the expression of any opinion whatsoever on the part of Research Square concerning the legal status of any country, territory, city or area or of its authorities, or concerning the delimitation of its frontiers or boundaries. This map has been provided by the authors. 


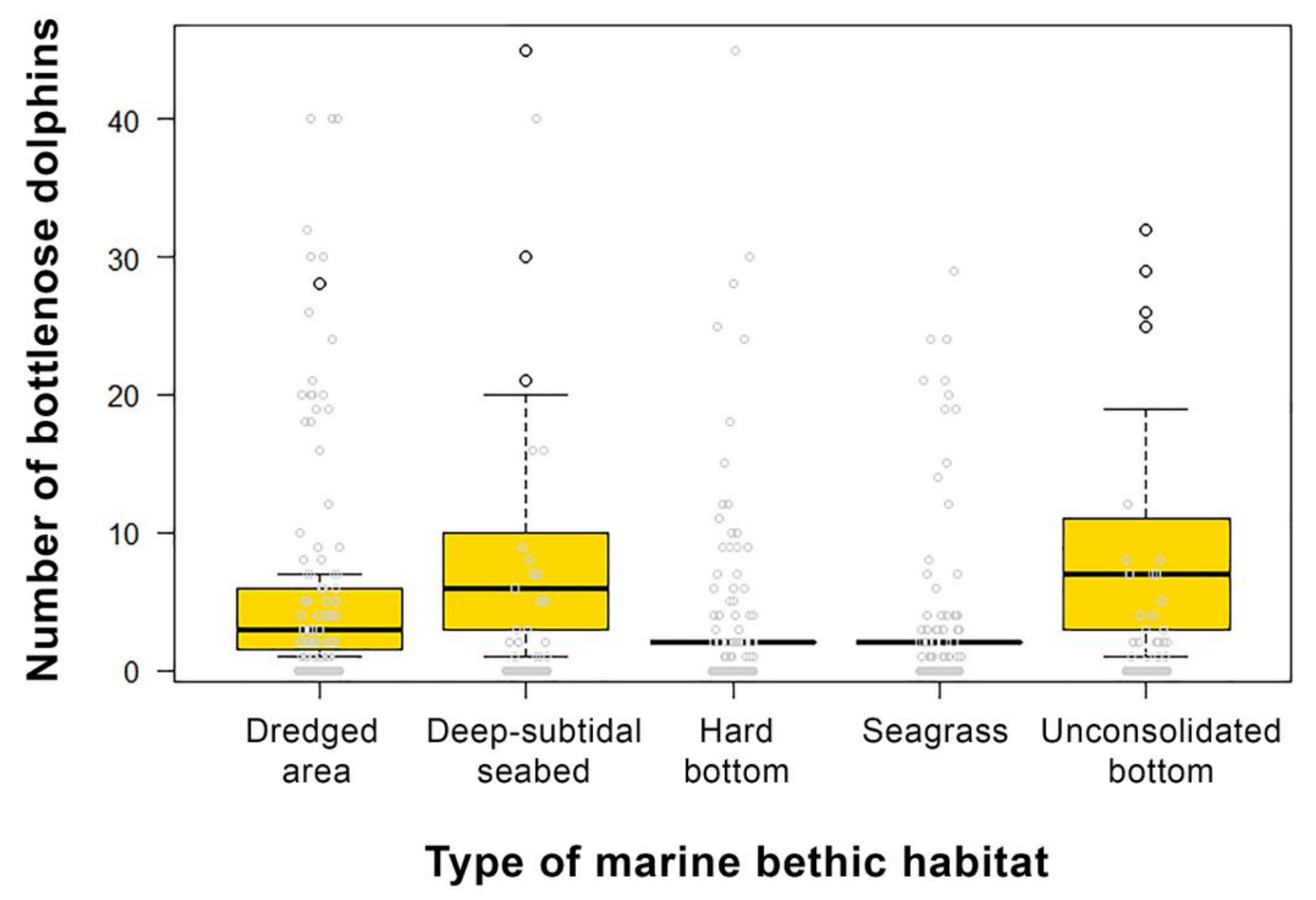

Figure 3

Size of the aggregations of bottlenose dolphins across the different marine benthic habitats.

\section{Supplementary Files}

This is a list of supplementary files associated with this preprint. Click to download.

- S1.tif

- S2.tif 